\title{
miR-98 functions as a tumor suppressor in salivary adenoid cystic carcinomas
}

This article was published in the following Dove Press journal:

OncoTargets and Therapy

23 March 2016

Number of times this article has been viewed

\author{
Xiaonan Liu' \\ Wenchao Zhang' \\ Hua Guo ${ }^{2}$ \\ Jiuling Yue ${ }^{\prime}$ \\ Shanshan Zhuo' \\ 'Department of Otorhinolaryngology \\ and Maxillofacial Oncology, \\ Tianjin Medical University Cancer \\ Institute and Hospital, ${ }^{2}$ Laboratory \\ of Cancer Cell Biology, National \\ Clinical Research Center of Cancer, \\ Key Laboratory of Cancer Prevention \\ and Therapy, Tianjin Cancer Institute, \\ Tianjin Medical University Cancer \\ Institute and Hospital, Tianjin, People's \\ Republic of China
}

Purpose: miR-98, a member of the let-7 family of microRNAs, is downregulated in many malignant tumors and has been correlated with tumor progression. However, the roles of miR-98 in salivary adenoid cystic carcinomas (SACCs) are still unclear. Thus, we explored the role of miR-98 in the pathogenesis of SACCs.

Methods: Reverse transcription-polymerase chain reaction was used to quantify miR-98 expression in SACC cell lines as well as in the primary tumors and adjacent tissues. Target gene prediction was carried out using softwares such as miRanda, PicTar, and TargetScan, and the neuroblastoma RAS viral oncogene homologue $(N-R A S)$ was chosen as a potential target gene. Subsequently, the regulatory role of miR-98 on N-RAS expression was examined by Western blotting and immunofluorescence assays. N-RAS expression was detected in SACC tissues and SACC cell lines using immunohistochemistry and Western blot, respectively. Furthermore, the associations between N-RAS expression and clinicopathological features were analyzed. Finally, the effects of miR-98 on the proliferation and metastasis of SACC cell lines were determined. Results: miR-98 was downregulated in primary tissues and ACC-M cells. Meanwhile, N-RAS expression was significantly higher in SACC tissues than that in the adjacent tissues, and its overexpression was significantly associated with the clinical stage and tumor size. In addition, the overexpression of miR-98 in ACC-M cells inhibited cell proliferation, invasion, and migration in vitro. It also significantly decreased the expression of N-RAS and inhibited signaling through the PI3K/AKT and MAPK/ERK pathways.

Conclusion: These results indicate that miR-98 possibly acts as a tumor suppressor in SACC by negatively regulating the oncogene $N-R A S$.

Keywords: miR-98, salivary adenoid cystic carcinoma, metastasis, $N-R A S$

\section{Introduction}

Adenoid cystic carcinoma (ACC) accounts for approximately $7.5 \%-10 \%$ of all malignancies in salivary glands. ${ }^{1}$ The clinical behavior of ACC is specific. Although it grows slowly, it readily invades the peripheral tissues and nerves. The main treatment option is surgical resection, followed by radiotherapy. Chemotherapies and biological treatments have shown poor effectiveness in the treatment of salivary adenoid cystic carcinoma (SACC)., ${ }^{2,3}$ The short-term survival of SACC is high, but the recurrence of SACC is common, and the occurrence of metastasis after 10 years decreases the long-term survival rate. ${ }^{4}$

MicroRNAs (miRNAs) are endogenous, noncoding small RNAs 19-25 nt in length that regulate target gene expression at the posttranscriptional level. ${ }^{5}$ The aberrant expression of miRNAs is closely related to tumorigenesis, tumor development, and the related treatment and prognosis. ${ }^{6}$ Recently, the presence and function of aberrant miRNAs in SACC were reported. ${ }^{7-9}$ Low levels of miR-155 expression were shown
Correspondence: Wenchao Zhang Department of Otorhinolaryngology and Maxillofacial Oncology,

Tianjin Medical University Cancer Institute and Hospital, Tianjin 300060,

People's Republic of China

Tel +8622 23340123

Email zwbeyond_999@sina.com (c) (i) (5) 2016 Liu et al. This work is published and licensed by Dove Medical Press Limited. The full terms of this license are available at https://www.dovepress.com/terms.php cC. hereby accept the Terms. Non-commercial uses of the work are permitted without any further permission from Dove Medical Press Limited, provided the work is properly attributed. For permission for commercial use of this work, please see paragraphs 4.2 and 5 of our Terms (https://www.dovepress.com/terms.php). 
to inhibit ACC-2 cell proliferation and invasion in vitro and suppress tumor growth and lung metastasis in vivo via the EGFR/NF- $\mathrm{BB}$ signaling pathway. ${ }^{7} \mathrm{miR}-181 \mathrm{a}$ was shown to suppress the metastasis of SACC by targeting the MAPKSnai2 pathway in vitro and in vivo. ${ }^{8}$ Meanwhile, the overexpression of miR-17 and miR-20a was significantly correlated with tumor size, clinical phase, and disease recurrence. High expression levels indicated a poor prognosis. ${ }^{10}$

miR-98/let-7 is a highly conserved small RNA family, and its members act as tumor suppressors in many malignant tumors. In esophageal squamous carcinoma, miR-98 is expressed at lower levels in $67.5 \%$ of cancer tissues. The expression level of miR-98 is related to the pathological grade of tumors, T stage, and lymph node metastasis. ${ }^{11}$ In breast cancers, miR-98 inhibits cancer cell proliferation, invasion, and angiogenesis by targeting activin receptor-like kinase-4 and matrix metalloproteinase-11. ${ }^{12}$ Meanwhile, miR-98 has been shown to improve treatment effects by binding to target mRNAs. In malignant melanomas, miR-98 was shown to inhibit tumor growth in vivo through its target gene $I l-6$ via the STAT3-NF-kB-lin28B signaling pathway. ${ }^{13}$ Research on prostate cancers has shown that the overexpression of miR-98 can inhibit tumor growth by improving the antiproliferative effects of 1alpha,25-dihydroxy vitamin D3 (1,25-VD). ${ }^{14}$ In hypoxic environments, the expression of miR-98 is downregulated in head and neck cancers and decreases the sensitivity to chemotherapy. ${ }^{15}$ However, the role of miR-98 in SACC and its ability to regulate malignant processes in SACC remain unclear.

The objective of the study was to determine whether miR-98 is a tumor suppressor in SACC and whether the overexpression of miR-98 can inhibit malignant biological behavior through its target gene, $N-R A S$.

\section{Materials and methods Tumor samples and cell lines}

ACC-M/SACC-83 are paired cell lines that were provided by Dr Li of Peking University, Beijing, People's Republic of China. The ACC-M cell line is more aggressive in terms of lung metastasis than SACC-83. ${ }^{16,17}$ Both cell lines were cultured in 1640 medium (Thermo Fisher Scientific, Waltham, MA, USA) supplemented with $10 \%$ fetal bovine serum (FBS; HyClone, Logan, UT, USA) at $37^{\circ} \mathrm{C}$ with $5 \% \mathrm{CO}_{2}$.

Fresh tissues were obtained from SACC patients undergoing surgery at Tianjin Medical University Cancer Institute and Hospital. All specimens were kept at $-80^{\circ} \mathrm{C}$ until use. In total, ACC tissue specimens were obtained from 43 cases between 2007 and 2014. All samples were embedded in paraffin. The patients' clinicopathological information was obtained from the patient's records. All the procedures were approved by the Institutional Review Board of Tianjin Medical University Medical Principle Committee. The patients who donated cells gave written informed consent.

\section{Real-time PCR}

Total RNA was isolated from the cells using microRNA mirVana miRNA Isolation Kits (Thermo Fisher Scientific), and cDNA was obtained using TaqMan ${ }^{\circledR}$ MicroRNA Reverse Transcription Kits (Thermo Fisher Scientific). The TaqMan ${ }^{\circledR}$ Universal PCR Master Mix II (Thermo Fisher Scientific) was used for real-time polymerase chain reaction (PCR). The following primers were used to amplify miR-98: sense, 5'-UGAGGUAGUAAGUUGUAUUGUU-3', antisense, 5'-AACAAUACAACUUACUACCUCA-3'. miR-98 levels were computed using the $2^{-\triangle \Delta C T}$ method, using U6 as an internal reference.

\section{miR-98 target gene prediction and luciferase reporter assay}

To determine the role of miR-98 in ACC, we adopted three bioinformatics algorithms, miRanda, PicTar, and TargetScan, to identify the potential target genes of miR-98. Given the roles of miR-98 in cell proliferation and invasion, we selected $N-R A S$ as a potential target gene. $N-R A S$ is a member of the RAS family, and it has an effect on cell proliferation and metastasis. ${ }^{18}$ We synthesized fragments containing the precise target sites for miR-98 in the $3^{\prime}$ untranslated region (UTR) of $N-R A S$ and then constructed luciferase reporter vectors bearing the target sites and mutant sites using a pGL-3 control vector (Promega Corporation, Fitchburg, WI, USA). The day before transfection, $293 \mathrm{~T}$ cells were plated onto 24-well plates $\left(1 \times 10^{5}\right.$ cells/well). Cells were transfected with the PGL-3 luciferase reporter vector, $\mathrm{pRL}-\mathrm{TK}$, with or without miR-98 mimics using Lipofectamine ${ }^{\circledR}$ transfection reagent. Luciferase activity was measured with the Dual Luciferase Reporter Assay System (Promega Corporation).

\section{Immunohistochemical staining}

A total of 43 paraffin-embedded tumor specimens were selected for this study. N-RAS antibody (1:50, Santa Cruz Biotechnology, Dallas, TX, USA) was the primary antibody used, and phosphate buffered saline (PBS) was used as a negative control. All immunostained sections were blindly independently evaluated by two pathologists. The intensity of immunostaining (negative $=0$, light yellow $=1$, light brown $=2$, brown $=3$ ) and the percentage of positive tumor 
cells $(\leq 5 \%=0,>5 \%-25 \%=1,>25 \%-50 \%=2,>50 \%-75 \%=$ $3,>75 \%=4)$ were assessed in at least five high-power fields (400× magnification). The final scores were multiplied by the intensity score and percentage score.

\section{Cell transfection}

miR-98 mimics (5'-UGAGGUAGUAAGUUGUAU UGUU-3') were synthesized by Thermo Fisher Scientific. Cells were seeded onto six-well plates $\left(3 \times 10^{5}\right.$ cells/well $)$ the day before the miR-98 mimics were transfected into ACC-M cells using Lipofectamine transfection reagent (Thermo Fisher Scientific) according to the manufacturer's instructions.

\section{Western blotting}

At 48 hours after transfection, total proteins were extracted. The proteins were separated by $10 \%$ sodium dodecyl sulfatepolyacrylamide gel electrophoresis and transferred to polyvinylidene fluoride (PVDF) membranes (Bio-Rad Laboratories Inc., Hercules, CA, USA). Blots were incubated with primary antibodies, including N-RAS (1:50, Santa Cruz Biotechnology), E-cadherin (1:2,500, BD Biosciences, San Jose, CA, USA), N-cadherin (1:250, BD Biosciences), vimentin (1:8,000, BD Biosciences), AKT (1:1,000, Cell Signaling Technology Inc., Danvers, MA, USA), p-AKT (1:1,000, CST), ERK1/2 (1:1,000, CST), p-ERK1/2 (1:1,000, CST), and $\beta$-actin (1:3,000, Santa Cruz Biotechnology), overnight at $4^{\circ} \mathrm{C}$. Then, the proteins were visualized using enhanced chemiluminescence reagent (Santa Cruz Biotechnology).

\section{Cell proliferation assay}

Cells were plated into 96 -well plates $\left(3 \times 10^{3}\right.$ cells/well). After transfection with miR-98 mimics or the control for 24, 48, 72, or 96 hours, $10 \mu \mathrm{L}$ MTT ( $5 \mathrm{mg} / \mathrm{mL}$, Promega Corporation) was added and incubated for 4 hours. Next, $150 \mu \mathrm{L}$ of DMSO was added to each well, and the optical density was detected at $490 \mathrm{~nm}$ after incubation for 15 minutes.

\section{Clone formation assay}

Cells were transfected as described earlier, and 1,000 cells were plated in $35 \mathrm{~mm}$ Petri dishes. The cells were then incubated for approximately 2 weeks at $37^{\circ} \mathrm{C}$ in a $5 \% \mathrm{CO}_{2}$ incubator. Colonies were stained with Giemsa and quantitated.

\section{Cell cycle analysis}

Transfected cells and control cells were trypsinized, washed with PBS, and fixed in $70 \%$ ethanol at $-20^{\circ} \mathrm{C}$ overnight. Then, the cells were washed with PBS, incubated in $50 \mu \mathrm{g} / \mathrm{mL}$ RNase for 30 minutes at $37^{\circ} \mathrm{C}$, and stained with propidium iodide for
10 minutes at $4^{\circ} \mathrm{C}$. Cell cycle phases were analyzed by flow cytometry (BD Biosciences).

\section{Cell migration assay to assess wound healing and chemotaxis}

A total of $3 \times 10^{5}$ cells from each cell line were plated in sixwell plates. When the cells were confluent, an artificial wound was created using a $10 \mu \mathrm{L}$ pipette tip 48 hours after transfection. Images were taken at two time points, 0 and 24 hours, using a Nikon Diaphot TMD inverted microscope $(10 \times)$. In addition, cell migration was measured by chemotaxis. The lower compartment was filled with $30 \mu \mathrm{L}$ epidermal growth factor (EGF), with different concentrations in each well $(0,1$, 10,100 , and $1,000 \mathrm{ng} / \mathrm{mL}$ ). In the upper compartment, $5 \times 10^{3}$ cells were added to each well. After 3 hours of incubation at $37^{\circ} \mathrm{C}$, nonmigrating cells were removed and invading cells were stained with crystal violet. Three random fields were captured by microscopy at $20 \times$ magnification .

\section{Transwell assay to assess cell invasion}

Cell invasion assays were performed using transwell membranes coated with Matrigel (BD Biosciences). After transfection, $1 \times 10^{5}$ cells in $200 \mu \mathrm{L}$ serum-free 1640 medium were seeded on the membrane. The lower chamber was filled with $20 \%$ FBS. After 48 hours, cells remaining in the upper chamber were removed, while invading cells were fixed with $3 \%$ paraformaldehyde and stained with crystal violet.

\section{Statistical analysis}

Data are expressed as the mean \pm standard deviation and were analyzed using SPSS17.0 software (SPSS Inc., Chicago, IL, USA). Student's $t$-test or chi-square test was used to compare differences between two groups. $P$-values of $<0.05$ were considered significant.

\section{Results}

miR-98 is expressed at lower levels while $\mathrm{N}$-RAS is overexpressed in tumor tissues and ACC-M cells

We examined the expression of miR-98 in fresh tumor tissues of ACC patients and in ACC-M/SACC-83 cell lines using qRT-PCR. miR-98 was expressed at lower levels in ACC-M cells than in SACC-83 cells ( $P<0.05$; Figure 1A). The expression of miR-98 in tumor tissues of ACC patients was lower than that in the adjacent controls $(P<0.05$; Figure $1 C)$. In contrast, $\mathrm{N}-\mathrm{RAS}$ showed higher expression in tumor tissues and ACC-M cells $(P<0.05$; Figure $1 \mathrm{~B}$ and D). These results suggested that miR-98 and N-RAS expression might be correlated. 
A

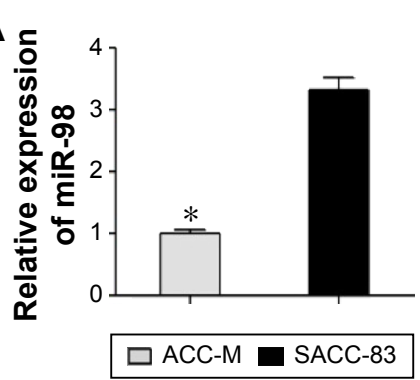

C

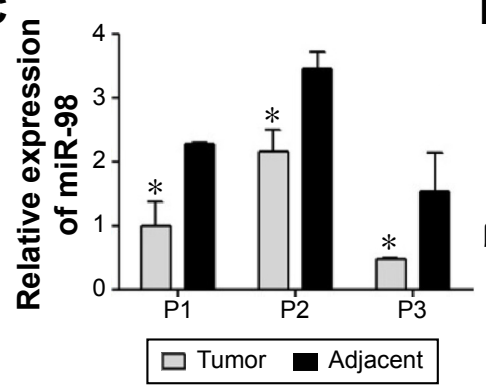

B

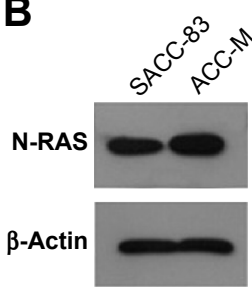

D

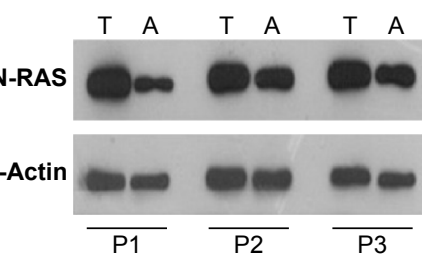

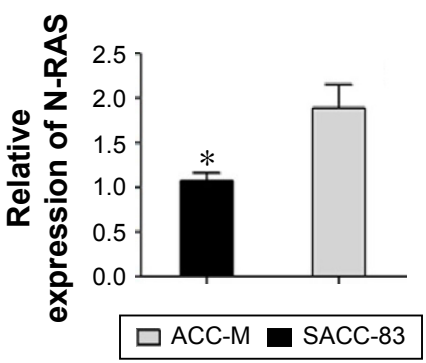

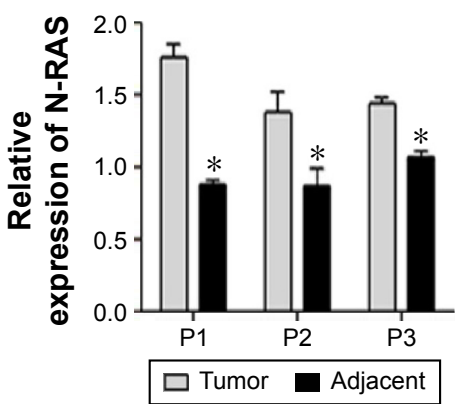

Figure I miR-98 and N-RAS levels in ACC-M/SACC-83 cell lines and ACC tumor tissues.

Notes: miR-98 expression was lower in ACC-M cells and tumor tissues ( $\mathbf{A}$ and $\mathbf{C})$. N-RAS was overexpressed in $\mathbf{A C C}-\mathbf{M}$ cells and tumor tissues $(\mathbf{B}$ and $\mathbf{D})$. $* \mathbf{P}<0.05$.

Abbreviations: ACC, adenoid cystic carcinoma; miR, microRNA; PI-P3, patients I-3; SACC, salivary adenoid cystic carcinoma.

\section{miR-98 negatively regulates the expression of N-RAS}

To investigate whether miR-98 regulates the expression of N-RAS, miR-98 mimics and a control were transfected into ACC-M cells. The expression of N-RAS in the two groups was detected by Western blotting and immunofluorescence assay. Figure 2A shows that miR-98 was successfully upregulated (55-fold) after transfection. Meanwhile, the expression of N-RAS was significantly reduced in miR-98-transfected cells (Figure 2B). The results of the immunofluorescence assay showed that N-RAS was expressed in the cytoplasm, and the fluorescence signal was abated in miR-98-transfected cells (Figure 2C). These results demonstrated that miR-98 negatively regulates the expression of N-RAS.
A

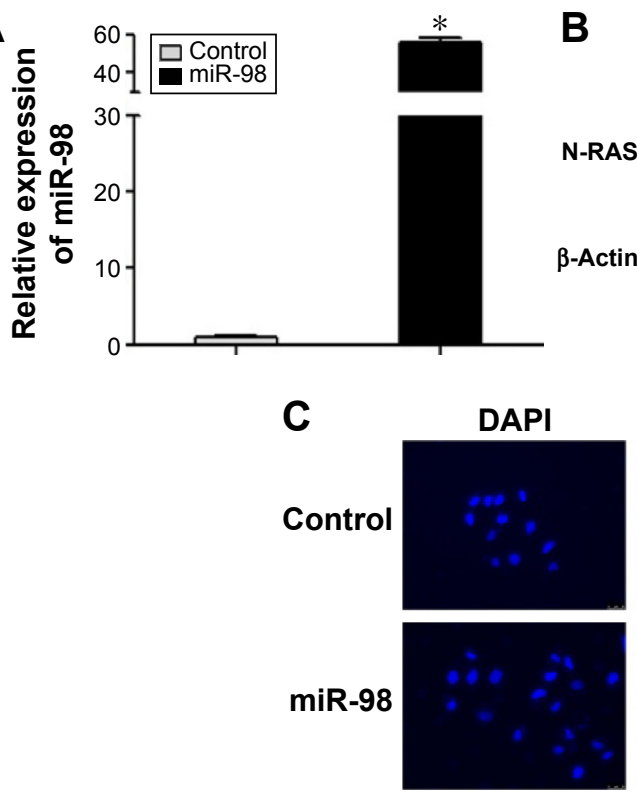

B

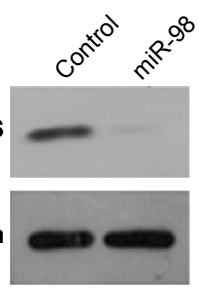

FITC
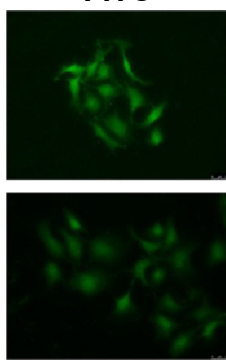
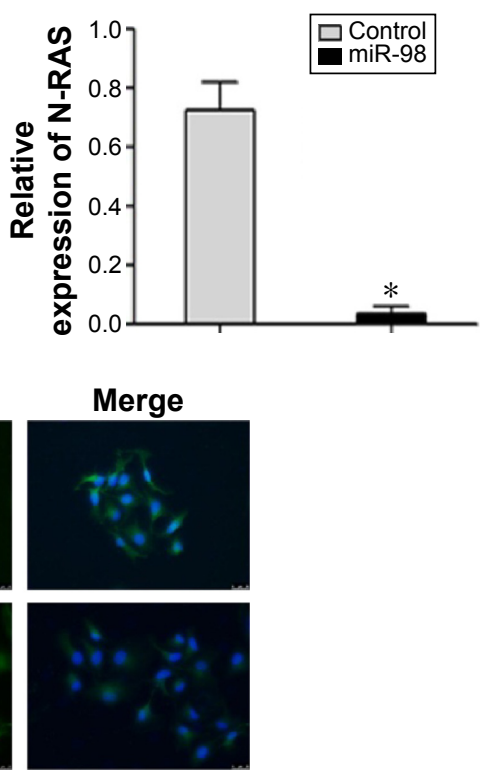

Figure 2 miR-98 regulates the expression of N-RAS.

Notes: $(\mathbf{A})$ miR-98 was significantly upregulated after the transfection of miR-98 mimics $* P<0.05$. (B) N-RAS was downregulated in miR-98-transfected cells $* P<0.05$. (C) $\mathrm{N}$-RAS was expressed in the cytoplasm, and the expression was significantly lower in miR-98 mimic-transfected cells than in control cells.

Abbreviation: miR, microRNA. 
A

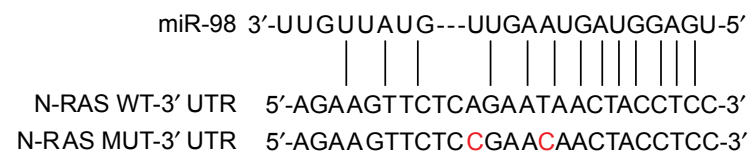

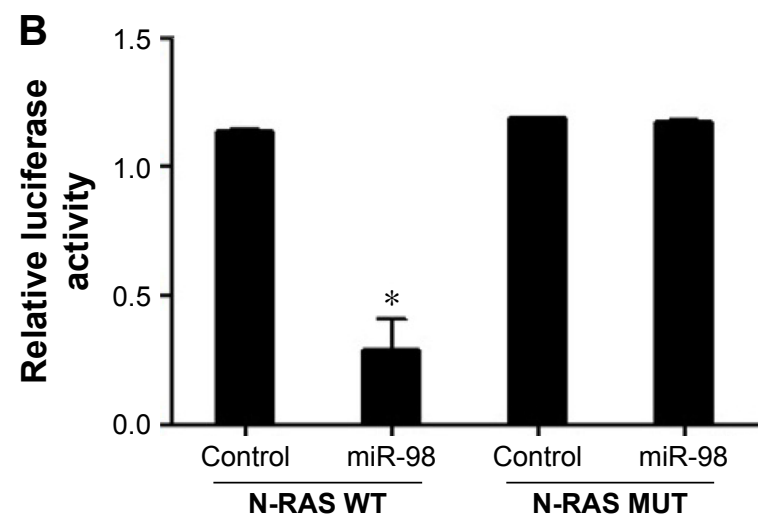

Figure 3 N-RAS is a direct target of miR-98.

Notes: (A) Sequence alignment between miR-98 and the human N-RAS 3' UTR. (B) Interactions between miR-98 and the 3' UTR of N-RAS were assessed by luciferase assay in 293 T cells. Luciferase activity was significantly decreased in miR-98 mimic-transfected cells in the wild-type groups, $* P<0.05$, while there were no obvious differences between the mutant-type groups.

Abbreviations: miR, microRNA; UTR, untranslated region; WT, wild type; MUT, mutant.

\section{miR-98 directly targets the $3^{\prime}$ UTR of N-RAS}

Bioinformatics analyses suggested that N-RAS might be a target of miR-98. The target sequence is shown in Figure 3A. To determine whether miR-98 directly regulates the expression of N-RAS, a luciferase reporter assay was performed in $293 \mathrm{~T}$ cells. As shown in Figure 3B, in the wild-type groups, luciferase activity was significantly decreased in cells transfected with miR-98 mimics, while there were no obvious differences between the mutanttype groups.

\section{The overexpression of N-RAS is significantly correlated with clinical stage and tumor size}

N-RAS was observed mainly in the cytoplasm of the tumor cells, and the expression rate in these cells was $83.7 \%$ (36/43). In normal salivary glands, N-RAS staining was only detected in some parotid duct epithelial cells (Figure 4D). As summarized in Table 1, N-RAS expression showed a significant, direct association with clinical stage and tumor size $(P<0.05)$, but not with sex, age, tumor histotype, or lymph node metastasis $(P>0.05)$.
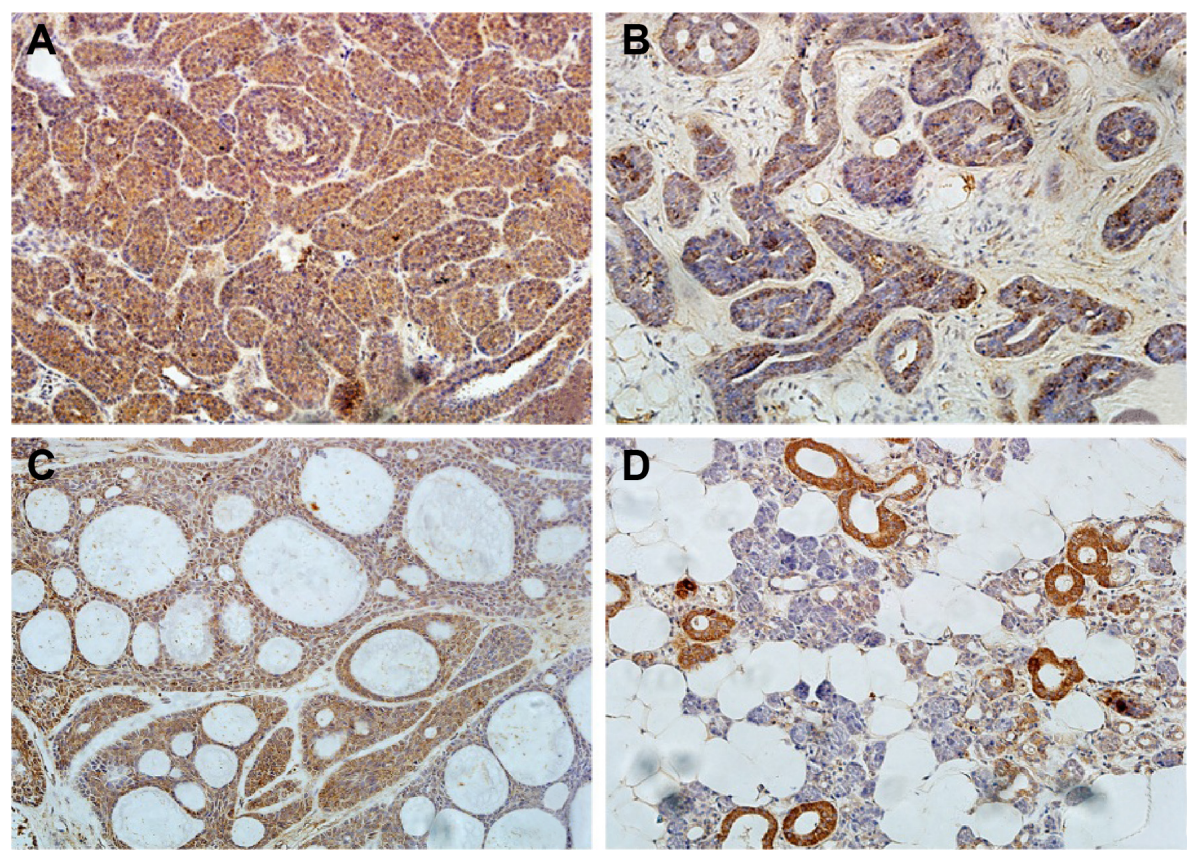

Figure 4 Immunohistochemical staining of N-RAS in ACC tissues.

Notes: N-RAS was expressed in the cytoplasm of the tumor cells in SACC tissue. N-RAS was highly expressed in all of three tumor histotypes, including solid (A), tubular (B), and cribriform (C). In adjacent normal tissues, N-RAS staining was only detected in some parotid duct epithelial cells (D). The image was captured by microscopy at $20 \times$ magnification. Abbreviations: ACC, adenoid cystic carcinoma; SACC, salivary adenoid cystic carcinoma. 
Table I Correlation between N-RAS expression and clinicopathological parameters in SACC

\begin{tabular}{|c|c|c|c|c|c|c|}
\hline \multirow[t]{2}{*}{ Variables } & \multirow[t]{2}{*}{$\mathbf{n}$} & \multicolumn{3}{|c|}{ N-RAS expression } & \multirow[t]{2}{*}{$x^{2}$} & \multirow[t]{2}{*}{$P$-value } \\
\hline & & - & + & ++ & & \\
\hline \multicolumn{7}{|l|}{ Sex } \\
\hline Male & 17 & 2 & 4 & 11 & 1.291 & 0.647 \\
\hline Female & 26 & 5 & 3 & 18 & 1.969 & 0.512 \\
\hline \multicolumn{7}{|l|}{ Age, years } \\
\hline$<50$ & 15 & I & 2 & 12 & 1.969 & 0.512 \\
\hline$\geq 50$ & 28 & 6 & 5 & 17 & & \\
\hline \multicolumn{7}{|l|}{ Stage } \\
\hline$I+I I$ & 21 & 7 & I & 13 & 10.864 & 0.002 \\
\hline III + IV & 22 & 0 & 6 & 16 & & \\
\hline \multicolumn{7}{|l|}{ Histotype } \\
\hline $\mathrm{C} / \mathrm{T}$ & 16 & 3 & 3 & 10 & 0.283 & 0.808 \\
\hline $\mathrm{S}$ & 27 & 4 & 4 & 19 & & \\
\hline \multicolumn{7}{|l|}{ LNM } \\
\hline Negative & 38 & 7 & 6 & 25 & 1.101 & 0.577 \\
\hline Positive & 5 & 0 & I & 4 & & \\
\hline \multicolumn{7}{|l|}{ Tumor size } \\
\hline$<4 \mathrm{~cm}$ & 25 & 7 & 2 & 16 & 7.660 & 0.018 \\
\hline$\geq 4 \mathrm{~cm}$ & 18 & 0 & 5 & 13 & & \\
\hline
\end{tabular}

Note: Bold figures are to show the significant variables $(P<0.05)$.

Abbreviations: C, cribriform; LNM, lymph node metastasis; S, solid; SACC, salivary adenoid cystic carcinoma; T, tubular.
miR-98 inhibits cell proliferation and clonogenicity of ACC-M cells by arresting the cell cycle in the $G_{0} / G_{1}$ phase

To study the effects of miR-98 expression on cell proliferation, we performed MTT and clone formation assays. Overexpression of miR-98 decreased cell viability (Figure 5A) and clonogenicity (Figure 5B; $P<0.05$ ). Moreover, after the upregulation of miR-98 expression in ACC-M cells, the proportion of cells in the $\mathrm{G}_{0} / \mathrm{G}_{1}$ phase increased from $48.02 \% \pm 1.17 \%$ to $59.25 \% \pm 1.00 \%$, and the proportion of cells in the S phase decreased from $35.28 \% \pm 2.18 \%$ to $20.03 \% \pm 0.46 \%$, providing evidence that miR-98 induces $\mathrm{G}_{0} / \mathrm{G}_{1}$ phase arrest in ACC cells.

\section{miR-98 inhibits migration and invasion of ACC-M cells}

To investigate the role of miR-98 in SACC, we evaluated the metastatic ability of ACC-M cells by transfection with miR-98 mimics or control miRNA. Wound healing and chemotaxis assays revealed that the percentage of migrating
A
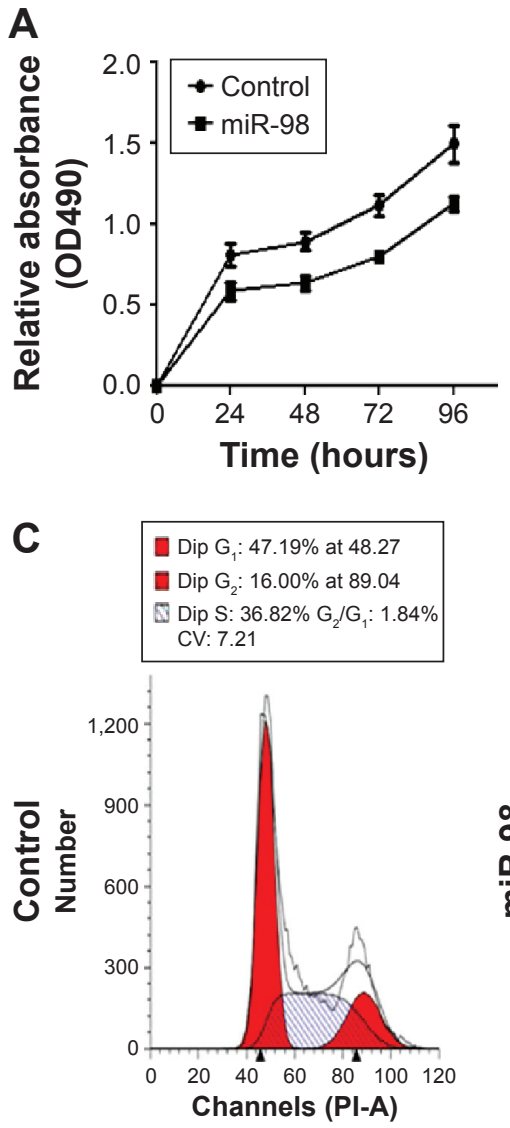

B
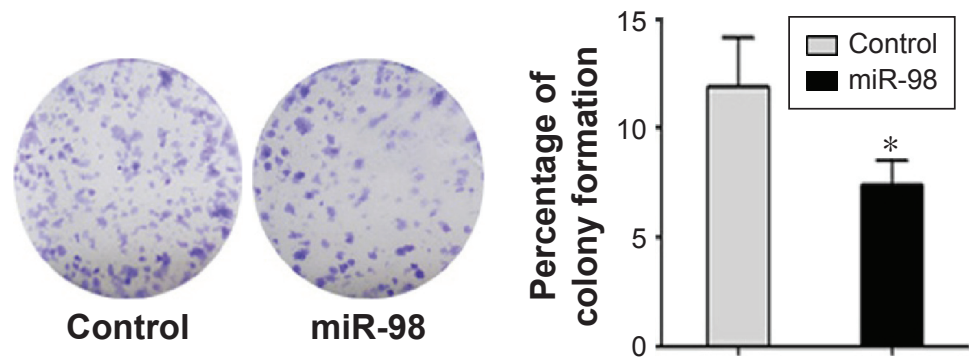
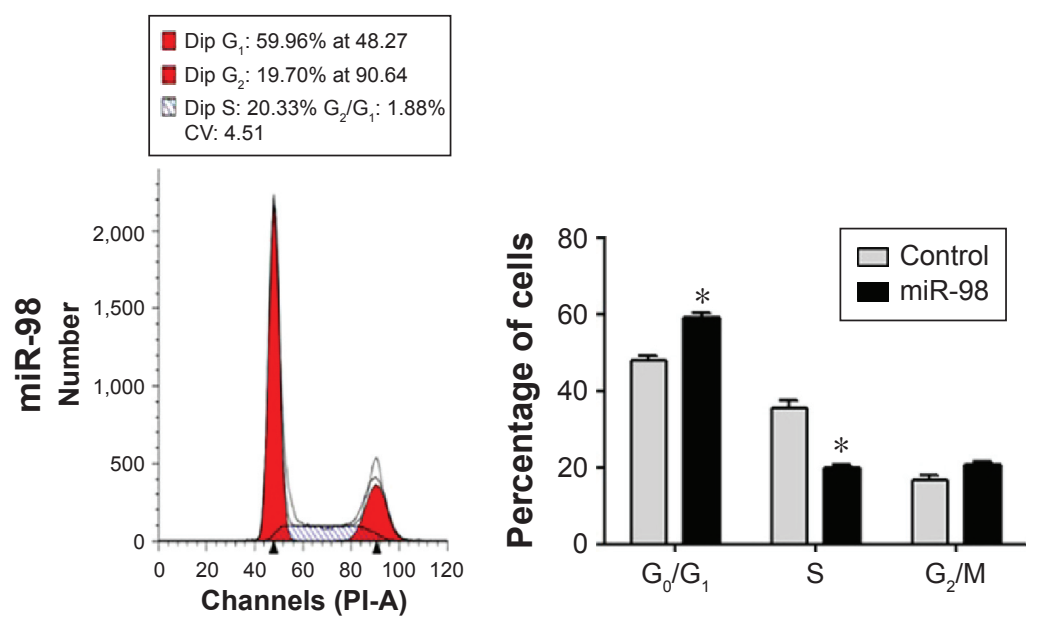

Figure 5 miR-98 inhibits cell viability and clonogenicity of ACC-M cells.

Notes: ACC-M cells were transfected with 50 pmol of miR-98 mimics. (A) MTT assay: the viability of miR-98-transfected cells was lower than that of the control group at 24, 48, 72, and 96 hours. (B) Clone formation assay: miR-98-transfected cells had a significantly lower survival rate than the control cells. (C) Cell cycle assay: the percentage of cells in the $\mathrm{G}_{1}$ phase was higher in miR-98-transfected cells than that in control cells. $* P<0.05$.

Abbreviations: ACC, adenoid cystic carcinoma; miR, microRNA; OD, optical density; PI-A, propidium iodide-area. 
miR-98-transfected cells was significantly lower than that of the control group (Figure 6A and $\mathrm{B} ; P<0.05$ ). In addition, in a transwell assay, we found that the percentage of miR98-transfected cells that invaded through the Matrigel ${ }^{\mathbb{B}}$ was lower than that of the control cells (Figure 6C; $P<0.05$ ). Furthermore, we assessed the expression levels of genes that are known to be associated with metastasis. As shown in Figure 6D, E-cadherin was upregulated, while N-cadherin and vimentin were downregulated in miR-98-transfected cells. These results indicated that miR-98 can inhibit the migration and invasion of ACC-M cells.
miR-98 inhibits signaling through the RAS/MAPK/ERK and PI3K/AKT pathways

After transfection, the expression of miR-98 was upregulated in ACC-M cells treated with miR-98 mimics (Figure 7A). To explore the role of $N-R A S$ in cell proliferation and metastasis, we examined the effect of miR-98 overexpression on the RAS/MAPK/ERK and PI3K/AKT pathways. As shown in Figure 7B, p-ERK and p-AKT were decreased in miR-98-transfected cells relative to the control. However, there were no differences in ERK1/2 and AKT expression levels between the two groups. These results suggested that
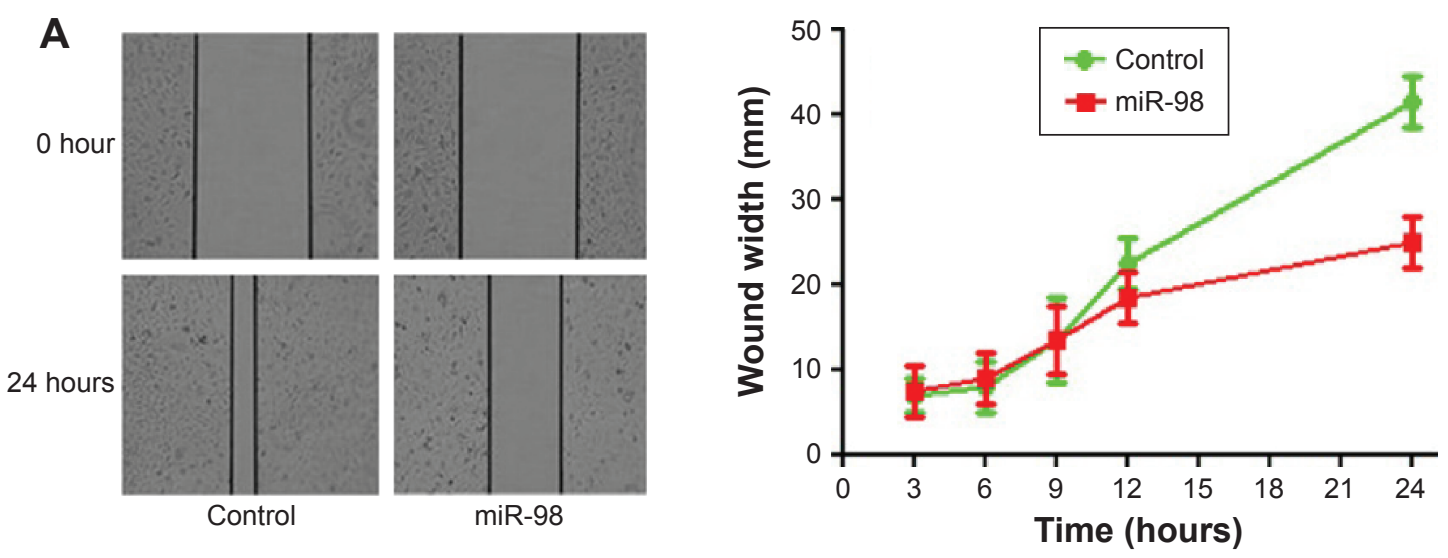

\section{B}

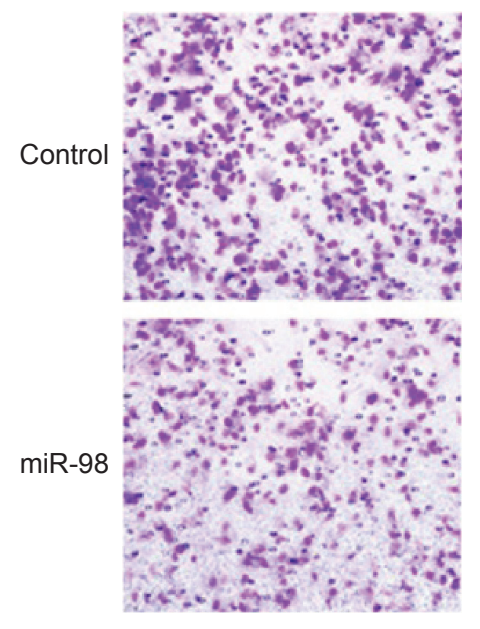

C

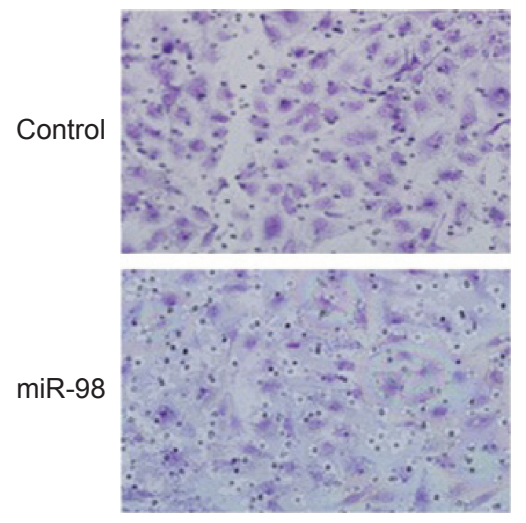

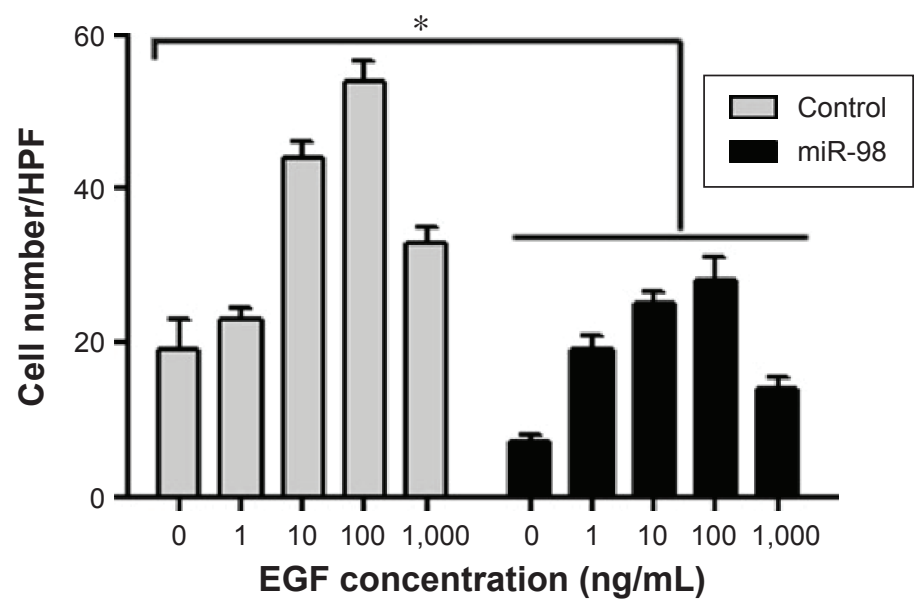

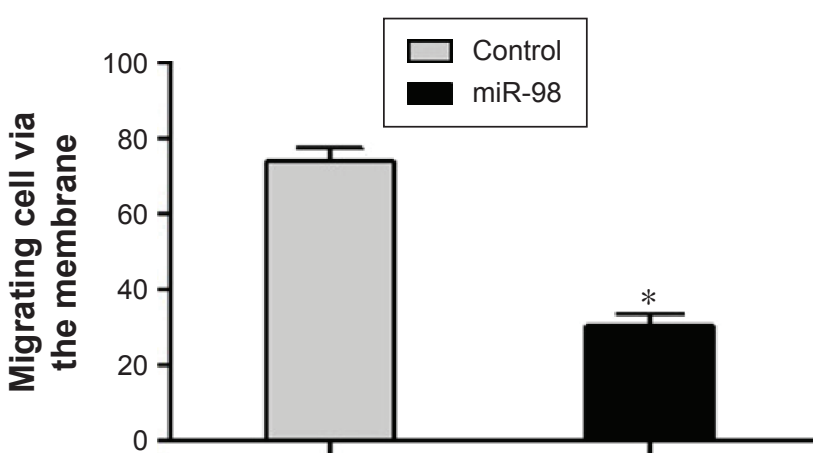

Figure 6 (Continued) 

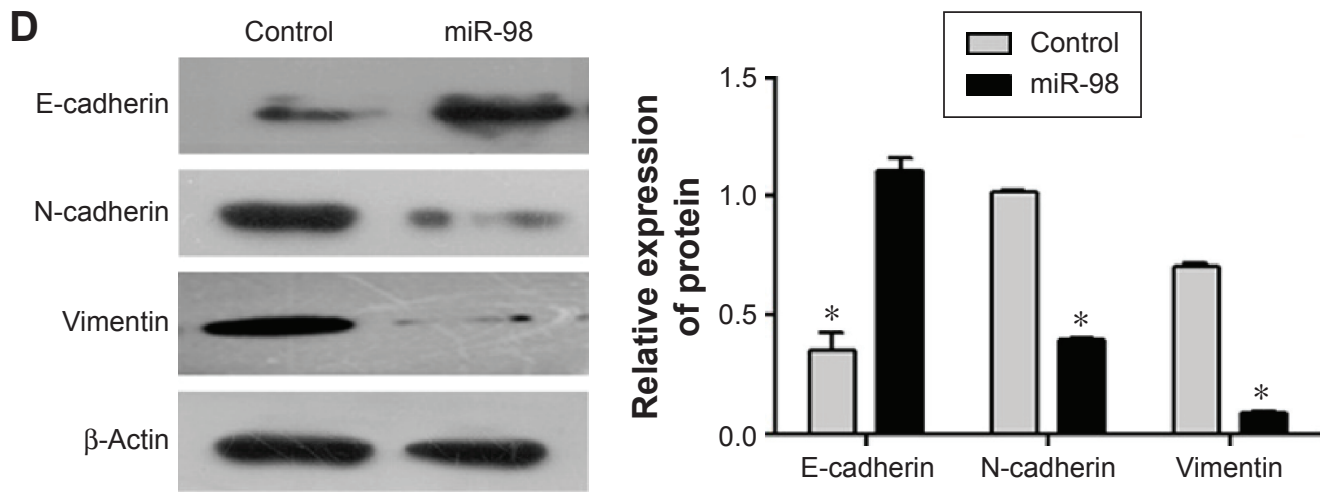

Figure 6 miR-98 inhibits migration and invasion of ACC-M cells.

Notes: ACC-M cells were transfected with 50 pmol of miR-98 mimics. (A) Wound healing assay: the wound width in miR-98-transfected cells was larger than that observed in the control cells. (B) Chemotaxis assay: the percentage of migrating miR-98-transfected cells was lower than that of the control. (C) Transwell assay: the percentage of cells that invaded through the Matrigel was lower in miR-98-transfected cells than in the control. (D) Assessment of the expression of genes associated with cell migration: $\mathrm{N}$-cadherin and vimentin were downregulated in miR-98-transfected cells, while E-cadherin was upregulated, relative to expression levels in the control cells. $* P<0.05$. Abbreviations: ACC, adenoid cystic carcinoma; HPF, high power field of microscope; miR, microRNA; EGF, epidermal growth factor.

miR-98 might suppress cell proliferation and metastasis through regulation of the $\mathrm{RAS} / \mathrm{MAPK} / \mathrm{ERK}$ and $\mathrm{PI} 3 \mathrm{~K} / \mathrm{AKT}$ pathways.

\section{Discussion}

miRNA plays an important role in SACCs, as it does in other malignant tumors. Here, we explored the expression of miR-98 in tissue samples from SACC cases and in two ACC cell lines. We found that miR-98 expression was significantly downregulated in ACC tumor tissues relative to adjacent normal tissues. In addition, miR-98 levels were lower in the highly metastatic ACC-M cell line than in the SACC-83 cell line. Through our experiments, we confirmed that the ACC-M cell line is a suitable model to study miR-98.

Although a considerable amount of evidence indicates that miR-98 has an impact on cell proliferation and metastasis in other tumor types, ${ }^{11,12}$ the function of miR-98 in SACC remains unknown. Therefore, we forced the expression of
miR-98 in ACC-M cells by transfection with miR-98 mimics. In our study, we found that the overexpression of miR-98 suppressed cell proliferation, clonogenicity, and metastasis in ACC-M cells. The epithelial-mesenchymal transition (EMT) is a key step in tumor metastasis and is characterized by the loss of E-cadherin and the gain of $\mathrm{N}$-cadherin and vimentin. ${ }^{19}$ Our results indicated that the increased expression of miR-98 may inhibit the migration and invasion of ACC-M cells by blocking the EMT process. Therefore, we concluded that miR-98 could be a tumor suppressor in ACC, due to its apparent antitumor activity.

miRNAs can regulate target genes by interacting with the $3^{\prime}$ UTR of the target gene mRNA, inhibiting translation, or promoting RNA degradation. Thus, we used three bioinformatics algorithms (miRanda, PicTar, and TargetScan) to identify miR-98 target genes, and $N$-RAS was selected as the candidate target gene. $N$ - $R A S$ encodes a small guanosine
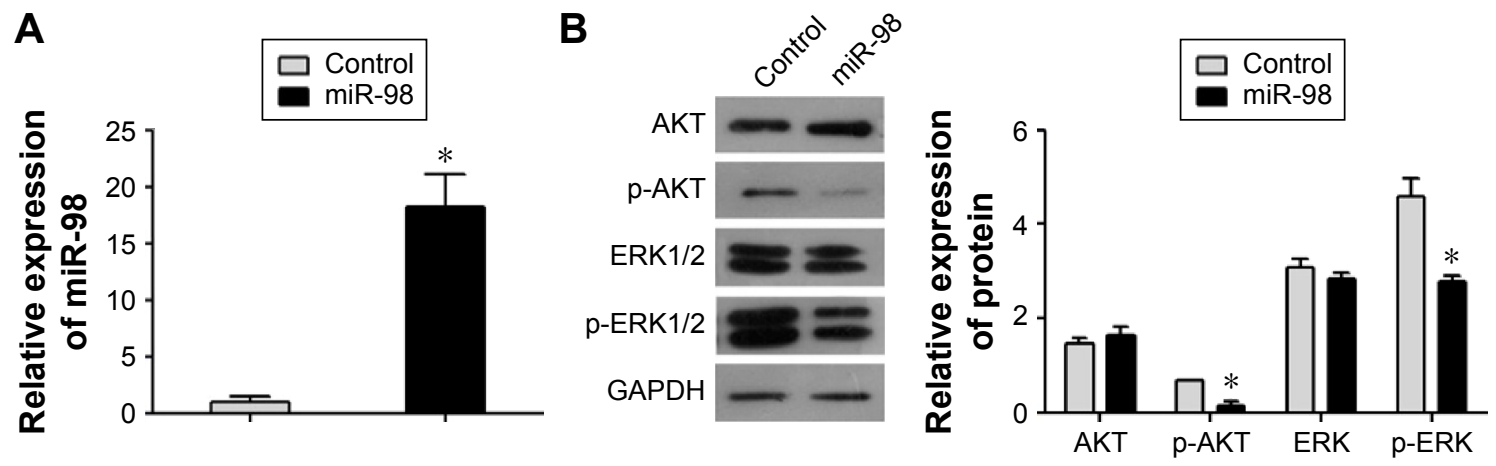

Figure 7 miR-98 inhibits signaling through the ERK and AKT pathways.

Notes: (A) miR-98 expression was upregulated in ACC-M cells transfected with miR-98 mimics. (B) P-ERKI/2 and p-AKT expression levels were lower in miR-98transfected cells as determined by Western blotting, while ERKI/2 and AKT protein levels remained unchanged. $* P<0.05$.

Abbreviations: ACC, adenoid cystic carcinoma; miR, microRNA. 
triphosphatase, which plays an important role in various biological processes, including proliferation, metastasis, and apoptosis. ${ }^{20}$ The expression levels of N-RAS have been shown to be related to the degree of cancer malignancy, including in gliomas and breast, pancreatic, and other cancers. ${ }^{21-24}$ The results of this study show that the expression of N-RAS can be regulated by miRNAs. ${ }^{18,25,26}$ In our study, N-RAS was validated as a novel target gene of miR-98. First, N-RAS was overexpressed in ACC-M cell line and tumor tissues. Second, N-RAS expression was downregulated in ACC-M cells that were transfected with miR-98 mimics. Third, a luciferase reporter assay confirmed that miR-98 directly targets the 3'UTR of N-RAS. Finally, the expression levels of N-RAS were significantly correlated with clinical phase and tumor size in SACC patients. Taken together, our data suggested that miR-98 acts as a tumor suppressor by targeting $N-R A S$ translation.

The RAS oncogene family is extraordinarily common in diverse cancers, and members of the family play important roles in tumorigenesis. ${ }^{27}$ RAS promotes tumorigenesis by activating several intracellular signal transduction cascades, including the RAS/MAPK/ERK and PI3K/AKT pathways. ${ }^{28,29}$ In gliomas, miR-143 inhibits N-RAS expression by these two pathways. ${ }^{18}$ However, in renal cell carcinomas, miR-134 functions as a tumor suppressor by targeting K-RAS in the RAS/MAPK/ERK pathway, apart from its function in the PI3K/AKT pathway. ${ }^{30}$ The results of this study showed that the overexpression of miR-98 decreased N-RAS expression, as well as the expression levels of p-ERK and p-AKT, indicating inactivation of the RAS/MAPK/ERK and PI3K/AKT pathways. This finding suggested that N-RAS may inhibit cell proliferation and metastasis through these two pathways.

\section{Conclusion}

In summary, our results show that miR-98 is downregulated in SACC and that miR-98 functions as a tumor suppressor by targeting N-RAS. Furthermore, miR-98 inhibits cell proliferation and metastasis via the regulation of the RAS/ MAPK/ERK and PI3K/AKT pathways. In addition, the overexpression of N-RAS is related to clinical stage and tumor size in SACC cases. However, since our results are derived from cell lines in vitro, further in vivo studies are required to explore the role of miR-98 and its therapeutic potential in SACC.

\section{Acknowledgment}

This work was supported by grant from the Science Foundation of Tianjin Medical University (2011ky13).

\section{Disclosure}

The authors report no conflicts of interest in this work.

\section{References}

1. Khafif A, Anavi Y, Haviv J, Fienmesser R, Calderon S, Marshak G. Adenoid cystic carcinoma of the salivary glands: a 20-year review with long-term follow-up. Ear Nose Throat J. 2005;84(10):662, 664-667.

2. Adelstein DJ, Koyfman SA, El-Naggar AK, Hanna EY. Biology and management of salivary gland cancers. Semin Radiat Oncol. 2012;22(3): 245-253.

3. Papaspyrou G, Hoch S, Rinaldo A, et al. Chemotherapy and targeted therapy in adenoid cystic carcinoma of the head and neck: a review. Head Neck. 2011;33(6):905-911.

4. Brazão-Silva MT, Cardoso SV, de Faria PR, et al. Adenoid cystic carcinoma of the salivary gland: a clinicopathological study of 49 cases and of metallothionein expression with regard to tumour behaviour. Histopathology. 2013;63(6):802-809.

5. Zamore PD, Haley B. Ribo-gnome: the big world of small RNAs. Science. 2005;309(5740):1519-1524.

6. Koturbash I, Zemp FJ, Pogribny I, Kovalchuk O. Small molecules with big effects: the role of the microRNAome in cancer and carcinogenesis. Mutat Res. 2011;722(2):94-105.

7. Liu L, Hu Y, Fu J, Yang X, Zhang Z. MicroRNA155 in the growth and invasion of salivary adenoid cystic carcinoma. J Oral Pathol Med.2013; 42(2):140-147.

8. He Q, Zhou X, Li S, et al. MicroRNA-181a suppresses salivary adenoid cystic carcinoma metastasis by targeting MAPK-Snai2 pathway. Biochim Biophys Acta. 2013;1830(11):5258-5266.

9. Sun L, Liu B, Lin Z, et al. MiR-320a acts as a prognostic factor and Inhibits metastasis of salivary adenoid cystic carcinoma by targeting ITGB3. Mol Cancer. 2015;14:96.

10. Mitani Y, Roberts DB, Fatani H, et al. MicroRNA profiling of salivary adenoid cystic carcinoma: association of miR-17-92 upregulation with poor outcome. PLoS One. 2013;8(6):e66778.

11. Huang SD, Yuan Y, Zhuang CW, et al. MicroRNA-98 and microRNA214 post-transcriptionally regulate enhancer of zeste homolog 2 and inhibit migration and invasion in human esophageal squamous cell carcinoma. Mol Cancer. 2012;11:51.

12. Siragam V, Rutnam ZJ, Yang W, et al. MicroRNA miR-98 inhibits tumor angiogenesis and invasion by targeting activin receptor-like kinase- 4 and matrix metalloproteinase-11. Oncotarget. 2012;3(11):1370-1385.

13. Li F, Li X, Qiao L, et al. miR-98 suppresses melanoma metastasis through a negative feedback loop with its target gene IL-6. Exp Mol Med. 2014;46(10):e116.

14. Ting HJ, Messing J, Yasmin-Karim S, Lee YF. Identification of microRNA-98 as a therapeutic target inhibiting prostate cancer growth and a biomarker induced by vitamin D. J Biol Chem. 2013;288(1):1-9.

15. Hebert C, Norris K, Scheper MA, Nikitakis N, Sauk JJ. High mobility group A2 is a target for miRNA-98 in head and neck squamous cell carcinoma. Mol Cancer. 2007;6:5.

16. Hu K, Li SL, Gan YH, Wang CY, Yu GY. Epiregulin promotes migration and invasion of salivary adenoid cystic carcinoma cell line SACC-83 through activation of ERK and Akt. Oral Oncol. 2009;45(2):156-163.

17. Dong L, Wang YX, Li SL, et al. TGF-beta1 promotes migration and invasion of salivary adenoid cystic carcinoma. J Dent Res. 2011;90(6): 804-809.

18. Wang L, Shi ZM, Jiang CF, et al. MiR-143 acts as a tumor suppressor by targeting N-RAS and enhances temozolomide-induced apoptosis in glioma. Oncotarget. 2014;5(14):5416-5427.

19. Kraljevic PS, Sedic M, Bosnjak H, Spaventi S, Pavelic K. Metastasis: new perspectives on an old problem. Mol Cancer. 2011;10:22.

20. Hancock JF. Ras proteins: different signals from different locations. Nat Rev Mol Cell Biol. 2003;4(5):373-384.

21. Li W, Liang R, Zhou $\mathrm{C}$, et al. The association between expressions of Ras and CD68 in the angiogenesis of breast cancers. Cancer Cell Int. 2015;15:17. 
22. Lo HW. Targeting Ras-RAF-ERK and its interactive pathways as a novel therapy for malignant gliomas. Curr Cancer Drug Targets. 2010; 10(8):840-848.

23. Bos JL. ras oncogenes in human cancer: a review. Cancer Res. 1989; 49(17):4682-4689.

24. Ali S, Ahmad A, Aboukameel A, et al. Increased Ras GTPase activity is regulated by miRNAs that can be attenuated by CDF treatment in pancreatic cancer cells. Cancer Lett. 2012;319(2):173-181.

25. Deng M, Tang H, Zhou Y, et al. miR-216b suppresses tumor growth and invasion by targeting KRAS in nasopharyngeal carcinoma. $J$ Cell Sci. 2011;124(Pt 17):2997-3005.

26. Johnson SM, Grosshans H, Shingara J, et al. RAS is regulated by the let-7 microRNA family. Cell. 2005;120(5):635-647.

27. Brossier NM, Prechtl AM, Longo JF, et al. Classic Ras proteins promote proliferation and survival via distinct phosphoproteome alterations in neurofibromin-null malignant peripheral nerve sheath tumor cells. J Neuropathol Exp Neurol. 2015;74(6):568-586.
28. Santarpia L, Myers JN, Sherman SI, Trimarchi F, Clayman GL, El-Naggar AK. Genetic alterations in the RAS/RAF/mitogen-activated protein kinase and phosphatidylinositol 3-kinase/Akt signaling pathways in the follicular variant of papillary thyroid carcinoma. Cancer. 2010;116(12):2974-2983.

29. Posch C, Moslehi H, Feeney L, et al. Combined targeting of MEK and $\mathrm{PI} 3 \mathrm{~K} / \mathrm{mTOR}$ effector pathways is necessary to effectively inhibit NRAS mutant melanoma in vitro and in vivo. Proc Natl Acad Sci USA. 2013;110(10):4015-4020.

30. Liu Y, Zhang M, Qian J, et al. miR-134 functions as a tumor suppressor in cell proliferation and epithelial-to-mesenchymal transition by targeting KRAS in renal cell carcinoma cells. DNA Cell Biol. 2015; 34(6):429-436.
OncoTargets and Therapy

\section{Publish your work in this journal}

OncoTargets and Therapy is an international, peer-reviewed, open access journal focusing on the pathological basis of all cancers, potential targets for therapy and treatment protocols employed to improve the management of cancer patients. The journal also focuses on the impact of management programs and new therapeutic agents and protocols on

\section{Dovepress}

patient perspectives such as quality of life, adherence and satisfaction. The manuscript management system is completely online and includes a very quick and fair peer-review system, which is all easy to use. Visit http://www.dovepress.com/testimonials.php to read real quotes from published authors. 